Aim of the study: Metastases from renal cell carcinoma represent between 0.25 and $3.00 \%$ of all resected pancreatic tumours. The aim of this study was to review 13 patients with renal cell carcinoma metastatic to the pancreas.

Material and methods: Clinical data, time from initial presentation, operative outcome, long-term survival, tumour size, presence of lymphatic invasion, and surgical margin status were evaluated.

Results: The median age of the patients was 62 years (mean 60.9). The median time for appearance of metastatic disease following resection of the primary tumour was 9 years (mean 8.38). Pancreatic metastases were located in the head of the pancreas in four patients, in the body in three, in the tail in two patients, and four patients had multiple pancreatic localisations. Four (30.7\%) pancreatoduodenectomies, 5 (38.5\%) distal resections, $2(15.3 \%)$ total pancreatectomies, 1 (7.6\%) enucleation, and 1 (7.6\%) Roux duodenojejunostomy were performed. Two patients (15.3\%) had postoperative complications. Operative mortality was $0 \%$. Surgical margins were microscopically positive in $1(8.3 \%)$ patient, and lymph nodes were positive in $2(16.6 \%)$ patients. In our group of 7 deceased patients the mean survival was 19 months (median 16 months).

Conclusions: Renal cell carcinoma metastatic to the pancreas can occur several years after nephrectomy. In our series a large number of patients with occurrence of symptoms, advancement of tumours, metastases to lymph node, and positive margin were connected with short survival period. Early detection of primary tumour, long and thorough patient care, and radical resections give patients a chance for a prolonged life.

Key words: metastases, pancreas, surgery, renal cell carcinoma.

Contemp Oncol (Pozn) 2014; 18 DOI: $10.5114 /$ wo.2014.45306

\section{Results of surgical management of renal cell carcinoma metastatic to the pancreas}

\author{
Katarzyna Kusnierz, Slawomir Mrowiec, Pawel Lampe
}

Department of Gastrointestinal Surgery, Medical University of Silesia, Katowice, Poland

\section{Introduction}

Metastatic lesions in the pancreas are rare and account for about 2-11\% of all pancreatic malignancies [1, 2]. Of resected pancreatic tumours, 0.25$3.00 \%$ of specimens are pathologically determined to be renal cell carcinoma (RCC), depending on the series [1]. In such cases, the differential diagnosis includes mainly primary pancreatic tumours, and the diagnosis of metastatic RCC is frequently made at the time of microscopic examination.

Most patients have widespread systemic diseases at the time of diagnosis. Pancreatic metastases are asymptomatic in more than $50 \%$ of cases; they are often detected during follow-up investigations after surgery for a primary lesion or as an incidental finding on imaging studies performed for an unrelated indication [2]. Symptoms, when present, are often nonspecific, such as abdominal pain, anaemia, weight loss, vomiting, nausea, jaundice, or gastrointestinal bleeding [3, 4].

The interval between nephrectomy and pancreatic metastasis is typically long, and has been reported up to 32 years [5]. The lesions are multifocal in about $30 \%$ of patients and resectable in $80 \%$ of patients [5]. It has been suggested that pancreatic metastases may arise from regional lymphatic dissemination because the pancreas and kidneys are located close to one another within the retroperitoneal compartment [6]. However, no relationship between the location of the metastasis within the pancreas and the site of the primary RCC has been demonstrated; left-sided tumours do not metastasise preferably to the tail of the pancreas, and pancreatic head metastases are not found predominantly in patients with right-sided tumours $[7,8]$.

Standardised pancreatic resection adapted to the location of the tumour in terms of partial pancreatoduodenectomy, distal pancreatectomy, and total pancreatectomy was generally recommended for the management of metastasis. Surgical resection of metastatic disease limited to the pancreas has a five-year survival rate of 29-35\% [9].

\section{Material and methods}

A retrospective review of 13 patients undergoing surgical management at the Department of Gastrointestinal Surgery for renal cell carcinoma metastatic to the pancreas was performed. Clinical data included sex, age, symptoms, medical history, time from initial presentation, other metastatic sites, operative outcome, and long-term survival after pancreatic resection. All patients underwent chest radiography, abdominal ultrasonography, and computed tomography (CT). The typical feature on CT was a hypervascularised pancreatic mass [10] (Fig. 1). Tumour size, histological type, the presence of lymphatic invasion, and surgical margin status were evaluated. All patients in the study had a known primary renal cell carcinoma, and the final pathology report on the pancreatic specimen was consistent with renal cell carcinoma. Patients with primary pancreatic malignancies were excluded. 


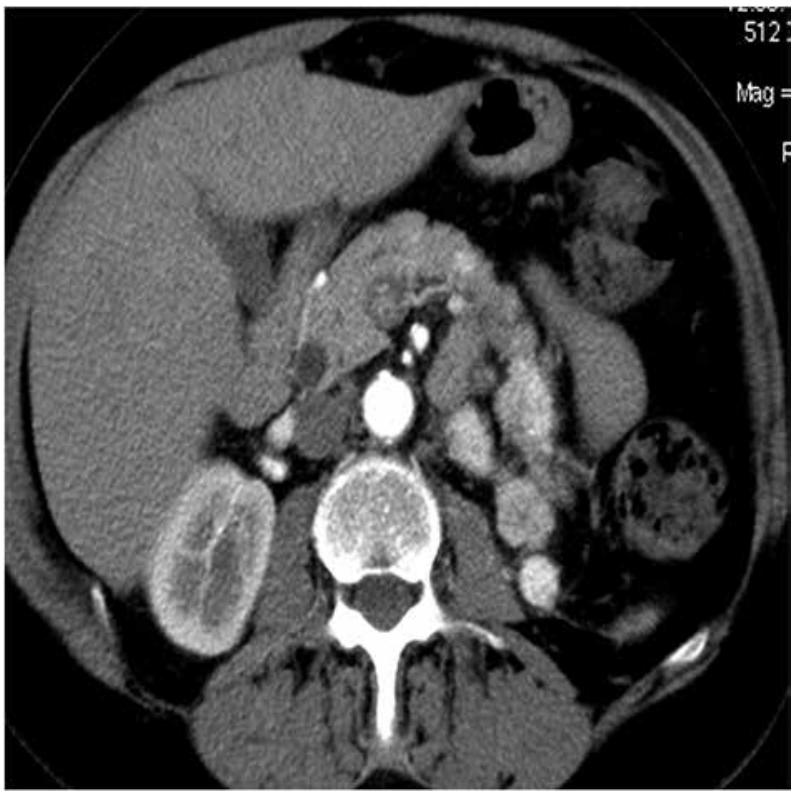

Fig. 1. A computed tomography scan of the abdomen showing pancreatic metastases from renal cell carcinoma with typical hypervascular features

All resections were standard resections in which only the lymph nodes in the tumour specimen were removed. Surgical morbidity and mortality were defined as occurring within 30 days of the operation. Follow-up information was obtained through the patient or the patient's family.

\section{Results}

Thirteen patients underwent surgery for isolated renal cell carcinoma metastases to the pancreas. The median age of the patients was 62 years (mean 60.9, range 33-70); there were 8 (61.5\%) female and 5 (38.4\%) male patients. Primary RCC originated from the left kidney in 5 patients (38.4\%) and from the right kidney in 8 (61.5\%). The median time for appearance of metastatic disease following resection of the primary tumour in this series was 9 years (mean 8.38, range 2-17). Symptoms of pancreatic involvement were variable. Abdominal pain was seen in 8 patients (61.5\%), vomiting in $4(30.7 \%)$, weight loss in 4 (30.7\%), obstructive jaundice in 2 (15.3\%), and gastrointestinal bleeding in 2 (15.3\%). Five patients (38.4\%) had no symptoms at all, with the pancreatic mass being found on routine follow-up radiologic imaging. Patient characteristics are shown in Table 1. One patient in the series, prior to developing a pancreatic metastasis, had metastases to the lung and the thyroid gland, all of which were resected.

Pancreatic metastases were located in the head of the pancreas in 4 patients (30.7\%), in the body in $3(23 \%)$, in the tail in $2(15.3 \%)$, and 4 patients (30.7\%) had multiple pancreatic localisations. A total pancreatectomy was performed in $2(15.3 \%)$ patients for multiple pancreatic metastases, 1 with splenectomy. Four (30.7\%) pancreatoduodenectomies, 2 of them as Whipple, 1 as Claget, and 1 as a pylorus preserving pancreatoduodenectomy, were performed for metastasis in the pancreatic head. For metastases in the pancreatic body and the tail, 5 (38.5\%)

Table 1. Patients characteristics and pattern of metastasis

\begin{tabular}{|c|c|c|c|c|c|c|}
\hline $\begin{array}{l}\text { Patient } \\
\text { No. }\end{array}$ & Sex & $\begin{array}{l}\text { Age } \\
(y r)\end{array}$ & $\begin{array}{l}\text { Kidney } \\
\text { RCC }\end{array}$ & $\begin{array}{l}\text { Years to } \\
\text { pancreatic } \\
\text { metastases }\end{array}$ & $\begin{array}{l}\text { Concomitant diseases and } \\
\text { medical history }\end{array}$ & Symptoms \\
\hline 1. & M & 33 & right & 3 & & abdominal pain, vomiting, weight loss \\
\hline 2. & M & 64 & right & 12 & diabetes, after cholecystectomy & abdominal pain, sweating \\
\hline 3. & M & 68 & right & 11 & after thyroidectomy (benign tumor) & $\begin{array}{l}\text { abdominal pain, upper gastrointestinal } \\
\text { bleeding, obstructive jaundice, vomiting }\end{array}$ \\
\hline 4. & $\mathrm{~F}$ & 70 & right & 14 & $\begin{array}{l}\text { diabetes, arterial hypertension, large bowel } \\
\text { diverticulosis, after cholecystectomy and } \\
\text { appendectomy }\end{array}$ & abdominal pain, weight loss, obstipation \\
\hline 5. & M & 70 & left & 3 & & $\begin{array}{l}\text { abdominal pain, upper gastrointestinal } \\
\text { bleeding, obstructive jaundice, vomiting }\end{array}$ \\
\hline 6. & M & 58 & right & 6 & arterial hypertension & abdominal pain, vomiting \\
\hline 7. & $\mathrm{~F}$ & 65 & right & 2 & liver cyst & no symptoms \\
\hline 8. & $\mathrm{~F}$ & 58 & left & 9 & $\begin{array}{l}\text { diabetes, after hysterectomy } \\
\text { (myoma uteri) }\end{array}$ & abdominal pain, weight loss \\
\hline 9. & M & 58 & right & 6 & & no symptoms \\
\hline 10. & $\mathrm{~F}$ & 62 & left & 9 & hypothyroidism & no symptoms \\
\hline 11. & $\mathrm{~F}$ & 61 & left & 17 & $\begin{array}{l}\text { after thyroidectomy (RCC metastasis to the } \\
\text { thyroid) ( } 15 \text { years after nephrectomy) and } \\
\text { metastasectomy (RCC metastasis to the lung) } \\
\text { (16 years after nephrectomy) }\end{array}$ & no symptoms \\
\hline 12. & $\mathrm{~F}$ & 68 & right & 15 & $\begin{array}{l}\text { after hysterectomy (myoma uteri), } \\
\text { cholecystectomy, appendectomy }\end{array}$ & abdominal pain, weight loss \\
\hline 13. & $\mathrm{~F}$ & 57 & left & 2 & $\begin{array}{l}\text { hypothyroidism, after hysterectomy } \\
\text { (myoma uteri) }\end{array}$ & no symptoms \\
\hline
\end{tabular}




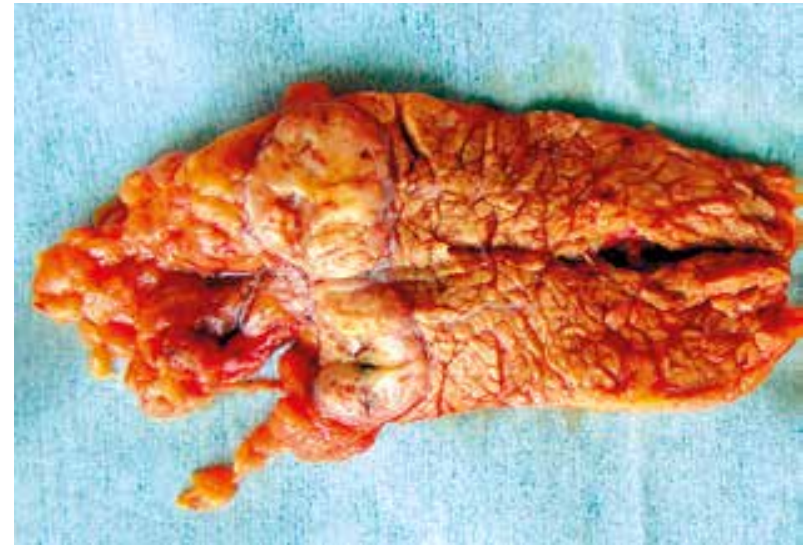

Fig. 2. Surgical specimen of the distal pancreatectomy with metastatic renal cell carcinoma

distal resections were performed (Fig. 2), 2 with splenectomy. Furthermore, we performed 1 (7.6\%) enucleation for metastasis in the body of the pancreas, together with a liver resection for simultaneous pancreatic and liver metastasis. In 1 (7.6\%) patient, resection was not performed because of locally advanced disease, and only Roux duodenojejunostomy was carried out. Twelve patients in our series underwent an elective surgical procedure, andone patient required urgent pancreatoduodenectomy. In the urgent case, this resulted from tumour erosion through the wall of the duodenum, leading to upper gastrointestinal bleeding.

Two patients (15.3\%) had postoperative complications. One patient $(7.6 \%)$ developed urethritis. One patient $(7.6 \%)$ with liver parenchymal bleeding required reoper-

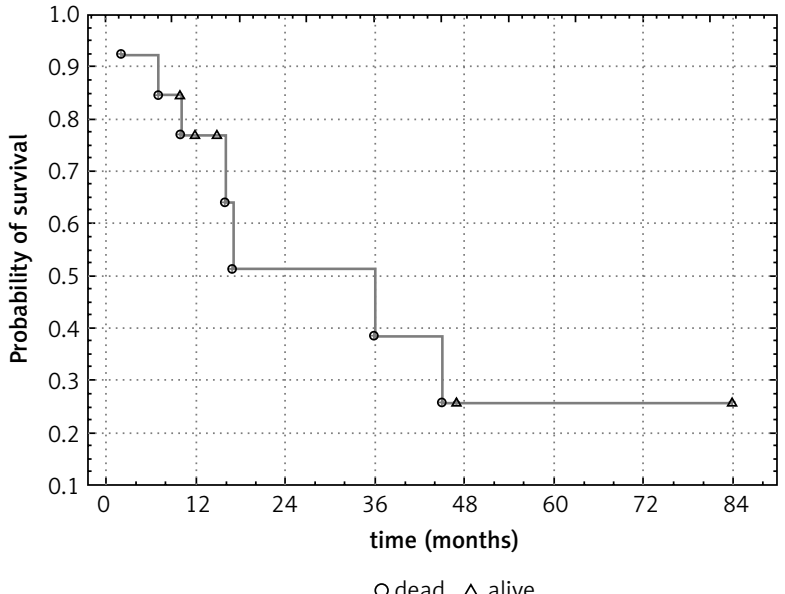

Fig. 3. Survival analysis and Kaplan-Meier survival curve

ation for haemostasis on the second postoperative day. Operative mortality was $0 \%$.

Patients median survival from the time of metastasectomy was 15 months (mean 24, range 2-84 months). Survival was defined for 31.12.2012. In our group of 7 deceased patients mean survival was 19 months (median 16 months). Survival analysis and Kaplan-Meier survival curve are presented in Figure 3. Details of surgical procedures and postoperative outcome are shown in Table 2.

Histologic examination of the resected specimens showed metastasis of renal cell carcinoma with the classic clear cell pattern. The median size of the metastatic tumours was $3 \mathrm{~cm}$ (mean 4.38, range $0.3-10 \mathrm{~cm}$ ). Surgical margins were microscopically positive (R1 resection) in $1(8.3 \%)$ of 12 patients undergoing resection. Lymph nodes

Table 2. Details of surgical procedures and postoperative outcome in patients undergoing surgery for pancreatic metastases from renal cell carcinoma

\begin{tabular}{|c|c|c|c|c|c|}
\hline $\begin{array}{l}\text { Patient } \\
\text { No. }\end{array}$ & $\begin{array}{c}\text { Site of } \\
\text { metastases }\end{array}$ & Procedure performed & $\begin{array}{l}\text { Postoperative } \\
\text { complications }\end{array}$ & $\begin{array}{l}\text { Survival } \\
\text { (mo) }\end{array}$ & Status \\
\hline 1. & $\begin{array}{l}\text { head, } \\
\text { body }\end{array}$ & $\begin{array}{l}\text { laparotomy, biopsy, } \\
\text { roux duodenojejunostomy }\end{array}$ & no & 10 & dead \\
\hline 2. & body & $\begin{array}{l}\text { distal pancreatectomy, } \\
\text { splenectomy }\end{array}$ & no & 16 & dead \\
\hline 3. & head & whipple pancreatoduodenectomy & $\begin{array}{c}\text { liver } \\
\text { parenchymal bleeding }\end{array}$ & 2 & dead \\
\hline 4. & tail & $\begin{array}{l}\text { distal pancreatectomy, splenectomy, } \\
\text { sigmoidectomy }\end{array}$ & no & 45 & dead \\
\hline 5. & head & $\begin{array}{l}\text { pylorus preserving } \\
\text { pancreatoduodenectomy }\end{array}$ & no & 7 & dead \\
\hline 6. & head & claget pancreatoduodenectomy & urethritis & 84 & alive \\
\hline 7. & body & $\begin{array}{l}\text { enucleation metastasis and excisio } \\
\text { liver metastasis }\end{array}$ & no & 17 & dead \\
\hline 8. & head, tail & total pancreatectomy & no & 47 & alive \\
\hline 9. & head & whipple pancreatoduodenectomy & no & 36 & dead \\
\hline 10. & body, tail & distal pancreatectomy & no & 15 & alive \\
\hline 11. & head, tail & total pancreatectomy, splenectomy & no & 12 & alive \\
\hline 12. & body & distal pancreatectomy & no & 12 & alive \\
\hline 13. & tail & distal pancreatectomy & no & 10 & alive \\
\hline
\end{tabular}


Table 3. Tumor characteristics

\begin{tabular}{|c|c|c|c|c|}
\hline $\begin{array}{l}\text { Patient } \\
\text { No. }\end{array}$ & $\begin{array}{c}\text { Histopathological } \\
\text { examination }\end{array}$ & $\begin{array}{l}\text { Tumor size }(\mathrm{cm}) \\
\text { and location }\end{array}$ & $\begin{array}{l}\text { Margins } \\
\text { status }\end{array}$ & $\begin{array}{c}\text { Lymph node } \\
\text { metastases }\end{array}$ \\
\hline 1. & MRCC & head and body - 10 & $\mathrm{~N} / \mathrm{A}$ & $\mathrm{N} / \mathrm{A}$ \\
\hline 2. & MRCC & body -4 & RO & N1 \\
\hline 3. & MRCC & head - 10 & RO & NO \\
\hline 4. & MRCC & tail - 4 & RO & NO \\
\hline 5. & MRCC & head - 3 & $\mathrm{R} 1$ & NO \\
\hline 6. & MRCC & head -5 & RO & NO \\
\hline 7. & MRCC & body -1.5 & RO & NO \\
\hline 8. & MRCC & head -3 , tail -4 & RO & N1 \\
\hline 9. & MRCC & head - 3 & RO & NO \\
\hline 10. & MRCC & body $-0.8,0.7$, tail -3 & RO & NO \\
\hline 11. & MRCC & head-3.5, tail-3 & RO & NO \\
\hline 12. & MRCC & body -4 & RO & NO \\
\hline 13. & MRCC & tail - 0.3, 0.5, 1 & RO & NO \\
\hline
\end{tabular}

were positive in 2 (16.6\%) of the 12 patients evaluated. Tumour characteristics and histological results are shown in Table 3.

\section{Discussion}

Common metastatic sites for RCC are lung, bone, liver, adrenal, brain, thyroid, gallbladder, pancreas, and muscle. Isolated solid organ metastasis to the pancreas occurs infrequently in the absence of widely disseminated disease. It is estimated that approximately one third of patients with RCC have metastases at presentation and that another $20-30 \%$ of patients with localised RCC will relapse after radical nephrectomy [9]. Although the majority of metastases occur within three years of radical nephrectomy, the appearance of metastatic disease many years after nephrectomy is a well-known feature of RCC [9]. Most of the studies reviewed report mean time intervals greater than 10 years, and a period as long as 32.7 years has been described [11]. Therefore, patients with a history of RCC should be monitored for more than 10 years after radical surgery to detect recurrence, especially distant metastasis [12]. No significant impact of time interval on disease-free or overall survival could be demonstrated, although patients with metachronous metastases occurring within two years of the primary RCC tended to have a poorer outcome [6]. In the opinion of some authors, the development of metastatic deposits after a prolonged disease-free period may actually be a negative prognostic indicator, implying a rapid and uncontrollable change in tumour biology [13]. In our experience, the median interval after nephrectomy was 9 years (mean 8.38, the longest interval was 17 years).

The average age of our patients at presentation (60.9 years) was similar to the findings reported in the literature (61.1 years) [14]. Patients with RCC may be completely asymptomatic, or they may develop symptoms of abdominal pain, gastrointestinal bleeding, jaundice, and weight loss. Hiotis et al. found that $69 \%$ of patients with isolat- ed pancreatic metastasis were completely asymptomatic at presentation [15]. In the current series, only 5 (38.5\%) patients had no symptoms. According to Sellner et al., in patients with symptoms, pain (20\%), gastrointestinal bleeding (20\%), weight loss (9\%), and jaundice (9\%) were the most common (in our study these were $61.5 \%, 30.7 \%$, $15.3 \%, 15.3 \%$, respectively) [8]. Interestingly, in the medical history of $4(30.7 \%)$ out of 13 of our patients, thyroid diseases were mentioned, and 3 (42.8\%) out of 7 women underwent hysterectomy because of uterine myoma. In our series, in 1 patient (7.6\%) pancreas was not the only site of metastasis at the time of surgery (liver metastasis). In 1 patient $(7.6 \%)$ the pancreas was the only site of metastasis during the operation, but another metastatic lesion in a different organ (lung and thyroid) had been removed previously. Previous disease recurrences, regardless of site, should not dissuade the surgeon from considering resection of pancreatic metastases if patients are otherwise free of disease at the time of observation [3]. In their series of 23 patients, Zerbi et al. noted a $34.8 \%$ rate of multifocal pancreatic metastases by pathological examination, but preoperative imaging had predicted multiple lesions far less often [3]. In our experience, 4 patients (30.7\%) had multiple pancreatic localisations. In the head of the pancreas in 4 patients (30.7\%), in the body in $3(23 \%)$, and in the tail in 2 (15.3\%), metastases were located. In the series by Thompson et al. the tumours seemed to involve the body and tail (33\%) slightly more frequently than other sites, but involvement of the head was nearly as common (29\%) [14]. In our study the mean size of the metastatic tumours was $4.38 \mathrm{~cm}$ (median $3 \mathrm{~cm}$ ). According to Thompson's et al. Review of the English Literature, the mean size of the metastatic tumours was $4.9 \mathrm{~cm}$ [14]. About 30-39\% of the metastases to the pancreas were multiple [5, 8]. The number and size of the pancreatic lesions did not show any significant association with either disease-free or overall survival [6]. No survival benefit was observed for those with solitary metastases, but survival was found to 
be significantly higher after an RO resection, independent of the number of tumour lesions. In the current study surgical margins were microscopically positive (R1 resection) in $1(8.3 \%)$ patient.

The current literature contains no data supporting medical treatment of patients with isolated pancreatic RCC metastases, even though there is some evidence that patients who do not undergo resection still have a reasonably long survival [5]. In almost all of the studies, pancreatic resection was recommended in the presence of isolated pancreatic localisation, and when technically feasible. The specific type of surgical resection will depend on the location of the tumour within the pancreas. These procedures range from pancreatoduodenectomy (for tumours in the head, neck, and uncinate process of the pancreas) to middle-segment or distal pancreatectomy (for tumours in the body and tail of the pancreas). In some instances, small isolated metastatic tumours to the pancreas can be treated with enucleation of the lesion, thereby preserving the pancreatic parenchyma $[16,17]$. In cases of multicentric pancreatic metastases, total pancreatectomy has been performed, although this treatment approach is uncommon [16]. Symptomatic, unresectable patients may still receive palliative surgery because of their relatively good prognosis. In the series by Bassi, $22.7 \%$ patients did not have surgical resection because of locally advanced disease [5]. Long-term survival of patients with renal cell carcinoma metastatic to the pancreas or periampullary region is better than that of patients with resected primary adenocarcinoma of the pancreas, and significantly better than that of patients with tumours metastatic from other sites [18]. Lymph node involvement is of uncertain prognostic significance; however, it occurs only rarely with RCC. Multifocality or larger metastatic nodules can lead to more extensive operations, but do not preclude long-term survival, as also documented by Sellner et al. [7, 8]. Given that many studies report no pancreatic lymph node involvement in the surgical specimens, radical lymph node dissection does not seem to be mandatory [19]. In the current study, lymph nodes were positive in $2(16.6 \%)$ patients.

The 5 -year survival rate ranged between $37 \%$ and $88 \%$ [6]. These differences in outcome may be explained by the small patient numbers and the wide variety of tumour characteristics; the percentage of symptomatic lesions ranged from 24 to $88 \%$, and metastases were synchronous in 0-29\% [6]. Ballarin had identified 18 studies addressing pancreatic metastasectomy for RCC with 5 or more patients [11]. Of the 12 studies that included long-term survival data (the 5 -year survival rate ranged between 0 and 100\%), 7 (58.3\%) reported 5-year survival rates from the time of the pancreatic metastasectomy higher than $80 \%$ [11]. In a series by Zerbi et al. conducted on surgically resected patients, 2 - and 5-year survival rates were $95 \%$ and $88 \%$, respectively [3]. Another literature review showed actuarial 3- and 5-year survival rates of $78 \%$ and $72 \%$, respectively [8]. Although our survival results are worse, ion our opinion surgery is effective for some patients in order to improve their survival. The mean live patient follow-up was 30 months (median 13.5 months). The longest survivor remains alive 84 months after resection. The large number of patients with the occurrence of symptoms, the advancement of tumours in our patients, metastases to lymph nodes, and one positive margin are probably connected with their short survival period. Early detection of primary RCC, effective surgical procedure (nephrectomy or nephron-sparing surgery), long and thorough patient care, radical, and pancreatic parenchyma saving resections give patients in this group a chance for a prolonged life [17, 20]. Pancreatic resections can nowadays be performed with low morbidity and mortality rates, in particular in high-volume centres [12].

\section{The authors declare no conflict of interest.}

\section{References}

1. Demirjian AN, Vollmer CM, McDermott DF, Mullen JT, Atkins MB, Callery MP. Refining indications for contemporary surgical treatment of renal cell carcinoma metastatic to the pancreas. HPB (Oxford) 2009; 11: 150-3.

2. Zerbi A, Pecorelli N. Pancreatic metastases: an increasing clinical entity. World I Gastrointest Surg 2010; 2: 255-9.

3. Zerbi A, Ortolano E, Balzano G, Borri A, Beneduce AA, Di Carlo V. Pancreatic metastasis from renal cell carcinoma: which patients benefit from surgical resection? Ann Surg Oncol 2008; 15: 1161-8.

4. Reddy S, Edil BH, Cameron JL, et al. Pancreatic resection of isolated metastases from nonpancreatic primary cancers. Ann Surg Oncol 2008; 15: 3199-206.

5. Bassi C, Butturini G, Falconi M, Sargenti M, Mantovani W, Pederzoli P. High recurrence rate after atypical resection for pancreatic metastases from renal cell carcinoma. Br J Surg 2003; 90: 555-9.

6. Tanis PJ, van der Gaag NA, Busch OR, van Gulik TM, Gouma DJ. Systematic review of pancreatic surgery for metastatic renal cell carcinoma. Br J Surg 2009; 96: 579-92.

7. Konstantinidis IT, Dursun A, Zheng H, Wargo JA, Thayer SP, Fernandez-del Castillo C, Warshaw AL, Ferrone CR. Metastatic tumors in the pancreas in the modern era. J Am Coll Surg 2010; 211: 749-53.

8. Sellner F, Tykalsky N, De Santis M, Pont J, Klimpfinger M. Solitary and multiple isolated metastases of clear cell renal carcinoma to the pancreas: an indication for pancreatic surgery. Ann Surg Oncol 2006; 13: 75-85.

9. Thadani A, Pais S, Savino J. Metastasis of renal cell carcinoma to the pancreas 13 years postnenhrectomv. Gastroenterol Hepatol (N Y) 2011; 7: 697-9.

10. Abbas MA, Collins JM, Mulligan DC. Renal cell carcinoma metastatic to pancreas. Am J Surg 2001; 182: 183-4.

11. Ballarin R, Spaggiari M, Cautero N, et al. Pancreatic metastases from renal cell carcinoma: The state of the art. World J Gastroenterol 2011; 17: 4747-56.

12. Wente MN, Kleeff J, Esposito I, Hartel M, Müller MW, Fröhlich BE, Büchler MW, Friess H. Renal cancer cell metastasis into the pancreas: a single-center experience and overview of the literature. Pancreas 2005; 30: 218-22.

13. Karimi KM, McFadden DW. Pancreatic resection for metastatic renal cell carcinoma to the pancreas. Am Surg 2007; 73: 1158-60.

14. Thompson LD, Heffess CS. Renal cell carcinoma to the pancreas in surgical pathology material. Cancer 2000; 89: 1076-88.

15. Hiotis SP, Klimstra DS, Conlon KC, Brennan MF. Results after pancreatic resection for metastatic lesions. Ann Surg Oncol 2002; 9: 675-9.

16. Lavu H, Yeo CJ. Metastatic renal cell carcinoma to the pancreas. Gastroenterol Hepatol (N Y) 2011; 7: 699-700.

17. Ohzato H, Yamamoto T, Fukunaga M, Imamura H, Furukawa $\mathrm{H}$. Middle-preserving pancreatectomy for multifocal metastatic renal cell carcinoma located in the head, body and tail of the pancreas. A case report. JOP 2010; 11: 633-7. 
18. Sohn TA, Yeo CJ, Cameron JL, Nakeeb A, Lillemoe KD. Renal cell carcinoma metastatic to the pancreas: results of surgical management. J Gastrointest Surg 2001; 5: 346-51.

19. Sotiropoulos GC, Lang H, Liu C, Brokalaki El, Molmenti E, Broelsch CE. Surgical treatment of pancreatic metastases of renal cell carcinoma. JOP 2005; 6: 339-43.

20. Luczyńska E, Dyczek S, Heinze-Paluchowska S, Komorowski A Pawlik T, Wysocki W, Klimek M. Nephrectomy or nephron-sparing surgery - how to decide? Contemp Oncol (Pozn) 2013; 17: 88-93.

\section{Address for correspondence}

Katarzyna Kusnierz MD, PhD

Department of Gastrointestinal Surgery

Medical University of Silesia

Medykow 14

40-752 Katowice, Poland

tel. +48604873800

fax +48 322525955

e-mail: kasiachir@wp.pl

Submitted: 6.12.2013

Accepted: 11.03.2014 